\title{
PATTERN OF DISOCCLUSION IN PATIENTS WITH COMPLETE CLEFT LIP AND PALATE
}

\author{
PADRÃO DE DESOCLUSÃO EM INDIVÍDUOS COM FISSURA LÁBIO-PALATINA COMPLETA
}

\author{
Daniella Andaluza Dias MATOS ${ }^{1}$, Marcelo Lucchesi TEIXEIRA², João Henrique Nogueira PINTO ${ }^{3}$, \\ José Fernando Scarelli LOPES ${ }^{3}$, Gisele da Silva DALBEN ${ }^{4}$
}

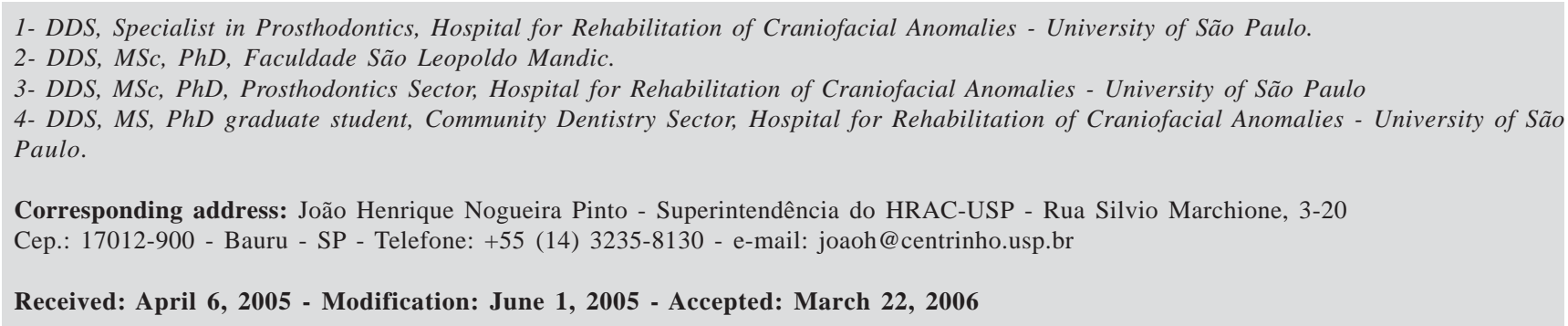

\begin{abstract}
$O$

bjective: to analyze the pattern of disocclusion during excursive mandibular movements and presence or absence of occlusal interferences and occlusal pathologies (gingival recession and abfraction). Method: examination of 120 individuals divided into two groups, as follows: Group 1 - 90 patients with complete cleft lip and palate (study group), subdivided into 30 patients with complete left unilateral cleft lip and palate, 30 patients with complete right unilateral cleft lip and palate and 30 patients with complete bilateral cleft lip and palate; Group 2 - 30 individuals without clefts (control group). Results: 58.8\% of patients in Group 1 presented unilateral or bilateral canine guidance, 26.6\% presented unilateral or bilateral group function and $54.4 \%$ presented lateral movements through the posterior teeth. Regarding protrusive movements, $80 \%$ presented anterior guidance and 20\% presented posterior guidance. In Group 2, 69.6\% of individuals presented unilateral or bilateral canine guidance, $43.2 \%$ presented unilateral or bilateral group function and only $13.3 \%$ presented lateral movements through the posterior teeth; $3.4 \%$ presented protrusion through the posterior teeth. Conclusions: there was no difference in the pattern of disocclusion between subgroups of patients with clefts. Group 2 presented predominance of bilateral group function, whereas Group 1 presented a higher prevalence of posterior guidance during lateral movements. Protrusion occurred primarily through anterior guidance in Group 2 and through the posterior teeth in Group 1. There was high prevalence of occlusal interferences at the molar area for both groups, yet with no correlation with occlusal pathologies (recession and abfraction).

Uniterms: Cleft lip and palate, disocclusion.
\end{abstract}

\section{RESUMO}

$O$ bjetivo: avaliar o padrão de desoclusão apresentado nos movimentos excursivos mandibulares e a presença ou não de interferências oclusais e patologias relacionadas à oclusão (recessão gengival e abfração). Método: exame de 120 indivíduos, divididos em 2 grupos: Grupo 1 - 90 pacientes com fissura completa de lábio e palato, subdivididos em 30 pacientes com fissura completa de lábio e palato unilateral esquerda, 30 pacientes com fissura completa de lábio e palato unilateral direita e 30 com fissura completa de lábio e palato bilateral; e Grupo 2 - 30 indivíduos sem fissuras (grupo controle). Resultados: 58,8\% do Grupo 1 apresentaram guia canina uni ou bilateralmente, 26,6\% apresentaram desoclusão com função em grupo uni ou bilateral e 54,4\% realizaram estes movimentos laterais através dos dentes posteriores; 80\% dos pacientes do Grupo 1 realizava protrusão pelos dentes anteriores e $20 \%$ pelos posteriores. Para o Grupo 2, guia canina uni ou bilateral foi observada em 69,6\% dos indivíduos, 43,2\% apresentaram função em grupo uni ou bilateral e somente 13,3\% realizaram os movimentos laterais pelos dentes posteriores. Apenas 3,4\% dos indivíduos do Grupo 2 apresentaram protrusão pelos dentes posteriores. Conclusões: não houve diferença estatisticamente significativa no padrão de desoclusão entre os subgrupos de pacientes com fissuras. $\mathrm{O}$ Grupo 2 apresentou predominância de função em grupo bilateral, enquanto o Grupo 1 apresentou maior prevalência de guia posterior durante os movimentos laterais. A protrusão ocorreu principalmente por guia anterior no Grupo 2 e pelos dentes posteriores no Grupo 1. Houve alta prevalência de interferências oclusais na região de molares para ambos os grupos, entretanto sem correlação com patologias oclusais (recessão e abfração).

Unitermos: Fissura lábio-palatina, desoclusão. 


\section{INTRODUCTION AND LITERATURE REVIEW}

Physiological stability of the masticatory system depends on proper occlusal balance. During excursive mandibular movements, oblique forces should be absorbed by structures that are able to support this type of load. Nevertheless, currently there is no consensus as to the ideal pattern of disocclusion, since the occlusal balance is related to contacts between teeth but also to biological, psychological and physiological features. Thus, occlusion may present alterations without any harmful consequences, due to the adaptive ability of the masticatory system ${ }^{16}$.

According to D'Amico ${ }^{5}$ (1958), ideal occlusion should have canine guidance during disocclusion, since the canines present higher proprioception and promote immediate interruption of tension on the masseter and temporalis muscles. On the other hand, Alexander ${ }^{1}$ (1963) stated that the canine does not have any special proprioceptive mechanism and that contacts between other teeth, thus characterizing group function, would lead to attrition and periodontal disease on the canines. Ramfjord and Ash ${ }^{18}$ (1984) advocated canine guidance, provided these teeth had a good bone support. Manns, et al. ${ }^{15}$ (1987), on the basis of electromyographic studies, also reported that canine guidance is more adequate than group function, because this type of disocclusion promotes lower muscular activity.

The literature is not very clear as to the incidence of types of disocclusion. Scaife ${ }^{20}$ (1969) found an incidence of $73 \%$ of canine disocclusion, whereas Ingervall ${ }^{12}$ (1972) observed canine disocclusion in only $20 \%$ of patients. Goldstein $^{7}$ (1979) studied the relationship between canine guidance and periodontium and observed that $14 \%$ of patients presented this type of disocclusion, $46 \%$ presented lateral disocclusion through group function and $24 \%$ presented different patterns of disocclusion on each side. Shefter and McFall Jr. ${ }^{21}$ (1984), in a similar study, observed canine guidance in $21 \%$ of subjects analyzed, group function in $46 \%$ and association of both in $27 \%$.

According to Scaife ${ }^{20}$ (1969), mutual protection (occlusion through posterior teeth and disocclusion through anterior teeth) presented an incidence of 5\%, which led them to conclude that this type of occlusion presents a relatively high occurrence, yet not necessarily predominant. Ingervall, et al. ${ }^{13}$ (1991), in a study of eccentric mandibular movements, observed that only one third of patients showed this type of occlusion. They also observed that, during protrusive movements, most patients presented contact in anterior teeth, whereas contacts only in posterior teeth were scarce.

Regarding occlusal interferences, Ingervall ${ }^{12}$ (1972) found that $30 \%$ to $50 \%$ of natural dentitions had these contacts on the non-working side, depending on the extension of movement of disocclusion. Grauer ${ }^{8}$ (1980) observed incidence of oclusal interferences of $20 \%$ on the working side, compared to 33\% on the non-working side. Okeson, et al. ${ }^{17}$ (1982) found incidence of $43.5 \%$ on the nonworking side during non-guided (voluntary) excursive mandibular movements. Laat and Steenberghe ${ }^{14}$ (1985) carried out an epidemiological study concerning occlusal relationships and temporomandibular joint dysfunctions and observed that $61 \%$ of the sample had unilateral or bilateral occlusal interferences.

According to Bassanta ${ }^{2}$ (1973) and Santos Junior ${ }^{19}$ (1991), the contacts between enamel surfaces of antagonist teeth produce wear facets on the working slopes of tooth cusps (physiological wear); nevertheless, wear facets in atypical areas suggest presence of parafunction. Braem, et al. $^{3}$ (1992) evaluated the etiologic potential of tension-type forces (occlusal overload) in the development of noncarious cervical lesions (abfraction) and observed different developmental stages among these lesions. According to the authors, the different etiologic mechanisms, namely acid, abrasive and occlusal stress, may interact in the development of this type of lesion or may act separately. However, if these lesions are subgingival, they may suggest the presence of load or unstable occlusal forces as the main etiology. Authors as Weinberg ${ }^{24}$ (1961), Scaife ${ }^{20}$ (1969), Shefter and McFall Jr. ${ }^{21}$ (1984) observed incidences of 84\%, $86 \%, 25.4 \%$ and $89 \%$ of wear facets, respectively.

Patients with cleft lip and palate present remarkable alterations in craniofacial growth and development, thereby presenting high prevalence of malocclusions of variable severity, which may be minimized or influenced by the dental treatment delivered, especially orthodontics, orthognathic surgery and prosthesis. These patients commonly present tooth agenesis, alterations in tooth morphology and especially in positioning, which may influence the physiological balance of the masticatory system. Thus, analysis of the pattern of disocclusion in these patients and detection of possible premature occlusal contacts and interferences is extremely important, since they may lead to muscular hyperfunction and development of masticatory forces that, in turn, may yield occlusal pathologies ${ }^{19}$.

No studies were found in the literature addressing the pattern of disocclusion in patients with clefts. Thus, the aim of this study was to analyze the pattern of disocclusion of patients with complete cleft lip and palate, verifying whether there is relationship between alterations in the pattern of occlusion (occlusal interferences) and presence of occlusal pathologies (gingival recession and abfraction).

\section{MATERIALAND METHODS}

The sample was composed of 120 individuals, being 60 males and 60 females, aged 20 to 35 years old, with a mean age of 27.5 years. From these, 90 presented complete cleft lip and palate (study group), who were examined during routine attendance at the Hospital for Rehabilitation of Craniofacial Anomalies -University of São Paulo. Patients with clefts were divided into three subgroups according to the type of cleft, with 30 individuals each: 1 - 30 patients with complete right unilateral cleft lip and palate (RUC), 2 30 patients with complete left unilateral cleft lip and palate (LUC), and 3 - 30 patients with complete bilateral cleft lip and palate (BC). These patients were compared to a control 
Clinical examination was performed by a single examiner (DADM) and included identification of tooth contacts in maximum intercuspation and location of premature contacts, with aid of articulating paper. The subjects were asked to perform lateral and protrusive movements for observation of the pattern of disocclusion and presence or absence of occlusal interferences. Occlusal pathologies, such as gingival recessions and abfractions, were evaluated on all teeth by visual inspection and were rated only as present or absent.

Data were analyzed through descriptive statistics, Fisher's test and chi-square test $\left(\mathrm{X}^{2}\right)$.

\section{RESULTS}

Since there was no statistically significant difference between the subgroups of patients with cleft regarding the variables analyzed, a single study group including the 90 individuals with clefts, and a control group of 30 individuals without clefts were evaluated.

Regarding the pattern of disocclusion presented by patients with complete cleft lip and palate, $58.8 \%$ presented unilateral or bilateral canine guidance, $26.6 \%$ presented unilateral or bilateral group function and $54.4 \%$ demonstrated unilateral or bilateral posterior guidance. Concerning the protrusive movement, $80 \%$ of patients presented anterior protrusion and $20 \%$ exhibited participation of posterior teeth. For the control group, unilateral or bilateral canine guidance was found in $69.6 \%$ of individuals; $43.2 \%$ presented unilateral or bilateral group function and posterior guidance was found in $13.3 \%$ of subjects. In relation to protrusion, $96.6 \%$ of individuals without clefts performed

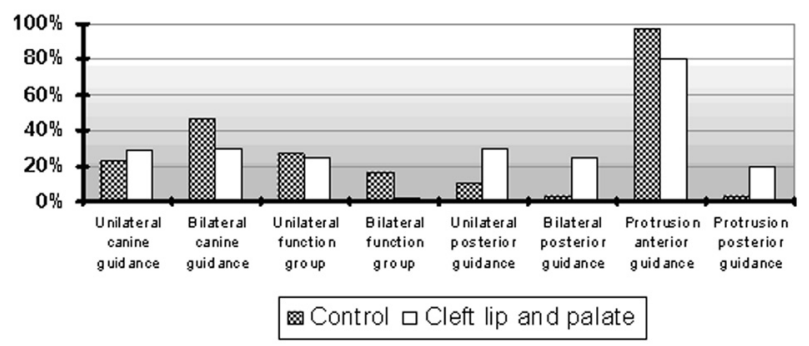

FIGURE 1- Pattern of disocclusion of the control and study groups for laterality and protrusion movements anterior protrusion and only $3.4 \%$ presented protrusion through posterior teeth.

Comparison between the study and control groups as to the pattern of disocclusion revealed statistically significant difference in bilateral group function $(\mathrm{p}=0.011)$, unilateral posterior guidance $\left(\mathrm{X}^{2}=4.80, \mathrm{p}=0.029\right)$, bilateral posterior guidance $\left(\mathrm{X}^{2}=6.47, \mathrm{p}=0.011\right)$, anterior protrusion $\left(\mathrm{X}^{2}=\right.$ $4.69, \mathrm{p}=0.022)$ and posterior protrusion $\left(\mathrm{X}^{2}=4.69, \mathrm{p}=\right.$ 0.022) (Figure 1).

Occlusal interferences during mandibular movements were present in $67.77 \%$ of patients in the study group, being $37.77 \%$ on right lateral movements and $30 \%$ on the left. Only $7.77 \%$ of this group presented occlusal interferences in protrusive mandibular movements. With regard to the control group, $60 \%$ presented occlusal interferences in laterality, being $33.33 \%$ on the right side and $26.67 \%$ on the left, and $13.33 \%$ of protrusion movements presented interferences (Figure 2).

The correlation between side of cleft and side of presence of occlusal interferences in the study group was not statistically significant according to the chi-square test $\left(\mathrm{X}^{2}\right.$ $=0.22, \mathrm{p}=0.638$ ).

Table 1 presents the correlation between occlusal interferences and occlusal pathologies (gingival recession and abfraction); the results demonstrated lack of statistical significance for both study and control groups.

\section{DISCUSSION}

Several authors ${ }^{5,15,18,22}$ believe that mutually protected

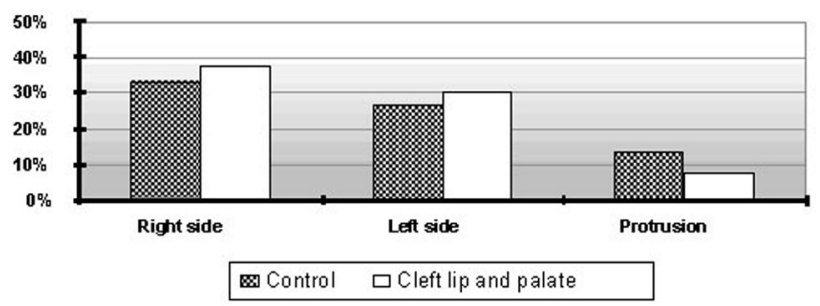

FIGURE 2- Prevalence of occlusal interference for right laterality, left laterality and protrusion movements, for the control and study groups

TABLE 1- Correlation between occlusal interferences and occlusal pathologies

\begin{tabular}{lccccc}
\hline Group $(\mathbf{n}$ of teeth) & Interference & \multicolumn{2}{c}{ Recession } & \multicolumn{2}{c}{ Abfraction } \\
\hline & & Yes & No & Yes & No \\
Control $(n=858)$ & Yes & $1^{\mathrm{a}}$ & $75^{\mathrm{a}}$ & $0^{\mathrm{b}}$ & $76^{\mathrm{b}}$ \\
& No & $39^{\mathrm{a}}$ & $743^{\mathrm{a}}$ & $8^{\mathrm{b}}$ & $774^{\mathrm{b}}$ \\
Cleft lip and palate & Yes & $20^{\mathrm{c}}$ & $174^{\mathrm{c}}$ & $1^{\mathrm{d}}$ & $193^{\mathrm{d}}$ \\
\hline
\end{tabular}

Results of chi-square test: $(a) x^{2}=2.100, p=0.14 ;(b) x^{2}=0.784, p=0.37 ;(c) x^{2}=0.259, p=0.61 ;(d) x^{2}=0.476, p=0.48$ 


\section{DISCUSSION}

Several authors ${ }^{5,15,18,22}$ believe that mutually protected occlusion (disocclusion through anterior teeth) is ideal, since the canine teeth present higher proprioception, are ideally located (thus promoting immediate disocclusion of posterior teeth), have considerable volume and bone support and present lower electromyographic activity, i.e. they promote higher muscular relaxation, besides presenting better conditions to distribute and afford occlusal loads without harmful consequences to posterior teeth and supporting structures. Conversely, authors who advocate disocclusion through group function ${ }^{1}$ believe that, if there are no contacts on the non-working side, teeth may distribute eccentric loads better than the canine in isolation, stating that this tooth does not have any special proprioceptive mechanisms.

Most patients with clefts presented canine disocclusion (58.8\%), followed by posterior disocclusion (54.4\%) and group function (26.6\%), in disagreement with the results obtained by Goldstein ${ }^{7}$ (1979) and Shefter and McFall Jr. ${ }^{21}$ (1984), in which most patients presented disocclusion through group function, with prevalence of $70 \%$ and $73 \%$, and prevalence of canine guidance of $38 \%$ and $48 \%$, respectively. This difference was expected, due to the remarkable occlusal discrepancy between patients with and without clefts. Nevertheless, Goldstein ${ }^{7}$, in 1979, concluded that patients presenting canine guidance also demonstrated lower periodontal index in relation to those with group function and progressive disocclusion. Moreover, the results of the present study are different from those obtained by Ingervall ${ }^{12}$ (1972), since they presented prevalence of canine guidance of only $19 \%$ and $20 \%$, respectively, whereas Laat and Steenberghe ${ }^{14}$ (1985) found comparable results for canine disocclusion (50\%) and group function (50\%).

The prevalence of canine disocclusion observed for the cleft group was similar to that found for the control group, allowing suggestion of the absence of influence from the presence of cleft lip and palate on the pattern of disocclusion.

The prevalence of occlusal interferences was also similar between the study and control groups, since they were observed in $67.77 \%$ in the study group and $60 \%$ in the control group. Such results also agree with other studies ${ }^{14,21}$, demonstrating that presence of the cleft, despite yielding occlusal discrepancies, does not increase the prevalence of individuals with this type of occlusal alteration after treatment for cleft repair. On the other hand, studies evaluating the prevalence of occlusal interferences revealed values of $30 \%$ to $50 \%{ }^{12}, 53 \%{ }^{8}$, and $43.5 \%^{17}$.

Despite the high prevalence of this occlusal alteration, there was no relation between the presence of occlusal interferences and occlusal pathologies (gingival recession and abfraction), both in the study and control groups. This is in agreement with Shefter and McFall Jr. ${ }^{21}$ (1984), who stated that occlusal alterations do not have any significant deleterious influence on the periodontium. On the other hand, several authors ${ }^{4,6,9,10,11,23}$ agree on the influence of occlusal interferences as great contributing factors in the etiology of occlusal traumas, progression of periodontal pathologies and development of articulation problems.

The incidence of occlusal interferences was higher at the molar area, being $84 \%$ for the study group and $80 \%$ for the control group, in agreement with results observed in other studies ${ }^{20,21,24}$.

This is a preliminary study on the pattern of disocclusion and prevalence of occlusal interferences and occlusal pathologies in patients with cleft lip and palate. Future studies should be conducted to confirm or complement the present findings, especially addressing the relationship between occlusal pathologies and toothbrushing habits, which was not investigated in the present study.

\section{CONCLUSION}

After analysis of the results, it could be concluded that: - there was no difference in the pattern of disocclusion between subgroups of patients with clefts;

- Group 2 presented predominance of bilateral group function, whereas Group 1 presented a higher prevalence of posterior guidance during lateral movements;

- protrusion occurred primarily through anterior guidance in Group 2 and through posterior teeth in Group 1;

- there was high prevalence of occlusal interferences at the molar area for both groups, yet with no correlation with occlusal pathologies (recession and abfraction)

\section{REFERENCES}

1- Alexander PC. Analysis of the cuspid protective occlusion. J Prosthet Dent. 1963;13(2):309-17.

2- Bassanta AD. Contribuição ao estudo das facetas de desgaste dos dentes naturais, no lado de trabalho, pelo método de estereofotogrametria. Rev Fac Odontol São Paulo. 1973;11(2):22333.

3- Braem M, Lambrechts P, Vanherle G. Stress-induced cervical lesions. J Prosthet Dent. 1992;67(5):718-22.

4- Caffesse RG. Management of periodontal disease in patients with occlusal abnormalities. Dent Clin North Am. 1980;24(2):215-30.

5- D'Amico A. Canine teeth-normal functional relation of the natural teeth of man. J South Calif Dent Assoc. 1958;26:6-24.

6- Genco RJ, Goldman HM, Cohen DW. Periodontia contemporânea. São Paulo: Ed. Santos; 1997.

7- Goldstein GR. The relationship of canine-protected occlusion to a periodontal index. J Prosthet Dent. 1979;41(3):277-83.

8- Grauer DE. Evaluating interferences in eccentric mandibular movement. Dent Surv. 1980;56(1):48-50.

9- Green MS, Levine DF. Occlusion and the periodontium: a review and rationale for treatment. J Calif Dent Assoc. 1996;24(10):19-27.

10- Harrel SK, Nunn ME. The effect of occlusal discrepancies on periodontitis. I. Relationship of initial occlusal discrepancies to initial clinical parameters. J Periodontol. 2001;72(4):485-94. 
11- Harrel SK, Nunn ME. The effect of occlusal discrepancies on periodontitis. II. Relationship of occlusal treatment to the progression of periodontal disease. J Periodontol. 2001;72(4):495-505.

12- Ingervall B. Tooth contacts on the functional and nonfunctional side in children and young adults. Arch Oral Biol. 1972;17(1):191200 .

13- Ingervall B, Hahner R, Kessi S. Pattern of tooth contacts in eccentric mandibular positions in young adults. J Prosthet Dent. 1991;66(2):169-76.

14- Laat A, Steenberghe D van. Occlusal relationships and temporomandibular joint dysfunction. Part I. Epidemiologic findings. J Prosthet Dent. 1985;54(6):835-42

15- Manns A, Chan C, Miralles R. Influence of group function and canine guidance on electromyographic activity of elevator muscles. J Prosthet Dent. 1987;57(4):494-501.

16- Neff PA. Occlusion and function. Washington: Georgetown University School of Dentistry; 1975.

17- Okeson JP, Dickson JL, Kemper JT. The influence of assisted mandibular movement on the incidence of nonworking tooth contact. J Prosthet Dent. 1982;48(2):174-7.

18- Ramfjord SC, Ash MM. Oclusão. Rio de Janeiro: Interamericana; 1984.

19- Santos Junior J. Oclusão: princípios e conceitos. São Paulo: Santos; 1991.

20- Scaife RR Jr. Holt JE: natural occurrence of cuspid guidance. J Prosthet Dent. 1969;22(2):225-9.

21- Shefter GJ, McFall Jr WT. Occlusal relations and periodontal status in human adults. J Periodontol. 1984;55(6):368-74.

22- Standlee JP, Caputo AA, Ralph JP. Stress transfer to the mandible during anterior guidance and group function eccentric movements. J Prosthet Dent. 1979;41(1):35-9.

23- Wank GS, Kroll YJ. Occlusal trauma. An evaluation of its relationship to periodontal prostheses. Dent Clin North Am. 1981;25(3):511-32.

24- Weinberg LA. The prevalence of tooth contact in eccentric movements of the jaw: its clinical implications. J Am Dent Assoc. $1961 ; 62: 402-6$ 